\title{
Nicos Poulantzas, a reprodução \\ capitalista e a luta de classes ${ }^{1}$
}

Angela Lazagna ${ }^{2}$

Resumo: Abordamos neste artigo as análises de Nicos Poulantzas sobre a relação entre classes sociais, reprodução de um modo de produção e transição de um modo de produção a outro. Para tanto, retomaremos as críticas desse autor à concepção economicista do conceito de classe, particularmente aquela formulada por Georg Lukács, a fim de evidenciar a originalidade da sua análise. Consideramos, ademais, algumas retificações e desenvolvimentos realizados por dois autores brasileiros, que compartilham das teses althusserianas e das contribuições de Poulantzas sobre o tema. Por fim, apresentamos um balanço da discussão acerca da operacionalidade do conceito de classe social na teoria da reprodução do modo de produção capitalista, bem como da sua transformação.

Palavras-chave: Poulantzas. Classes Sociais. Modo de produção.

Abstract: We discuss in this article the Nicos Poulantzas' analysis on the relation between social classes, reproduction of a mode of production and transition from one mode of production to another. To that end, we will return to the criticism of this author to the economistic conception of the class' concept, particularly that formulated by Georg Lukács, in order to highlight the originality of his analysis. We consider, in addition, some corrections and developments made by two Brazilian authors, who share the Althusserian theses and the Poulantzas' contributions on the subject. Finally, we present a balance

\footnotetext{
${ }^{1}$ Este artigo é uma versão modificada do item 2.2. "A reprodução do modo de produção capitalista e a luta de classes" da minha tese de doutorado. Ver Lazagna (2017).

2 Pós-doutoranda (PDJ/CNPq), PPGH - Universidade Federal Fluminense (UFF). E-mail: alazagna@gmail.com
} 
of the discussion about the operability of the concept of social class in the theory of the reproduction of the capitalist mode of production, as well as its transformation.

Keywords: Poulantzas. Social classes. Mode of production.

\section{Introdução}

As décadas de 1960 e 1970 vivenciaram uma renovação teórica no campo do marxismo em virtude do aparecimento de uma nova interpretação da teoria marxista da história, convencionalmente denominada materialismo histórico pela tradição posterior aos fundadores do marxismo. Esse contexto é marcado por uma interpretação inovadora do lugar do político (ou estrutura jurídicopolítica) e da política (ou prática política) nas análises marxistas dos processos de reprodução e transformação social. O rigor que guiou esta reinterpretação dos escritos de Marx e Engels foi protagonizado por um grupo de autores que se reuniu sob a liderança do filósofo francoargelino Louis Althusser. No que se refere ao seu aspecto mais geral, o resultado desse trabalho teórico foi a reafirmação e a instauração dos fundamentos de um "materialismo histórico renovado" ${ }^{3}$, que oferece uma reinterpretação da explicação marxista da história concernente tanto às formas de reprodução dos modos de produção particulares (escravista, feudal, capitalista...) quanto às formas de transição de um modo de produção a outro ${ }^{4}$.

Nicos Poulantzas, cientista político marxista, escreveu, a partir das concepções desenvolvidas por Althusser, um ambicioso tratado

\footnotetext{
3 As principais teses desse "materialismo histórico renovado" estão presentes nas obras diretamente envolvidas naquele trabalho: a obra individual de Louis Althusser, Pour Marx, e a obra coletiva, coordenada por Althusser, Lire Le Capital.

${ }^{4}$ No entanto, a despeito de concederem a mesma importância a esses diferentes objetos da prática teórica - reprodução e transformação -, as análises da corrente althusseriana se debruçaram com mais afinco sobre os processos sociais reprodutivos, em particular, sobre o funcionamento reprodutivo do modo de produção capitalista.
}

\begin{tabular}{l|l}
\hline 114 & Nicos Poulantzas,...
\end{tabular} 
marxista de ciência política intitulado Pouvoir politique et classes sociales (PPCS). É possível dizer que dois grandes temas, que fundamentalmente informam as teses expostas nesta obra e que podem nos conduzir na sua leitura, são aqueles relativos à função do Estado, tema ligado à questão da reprodução capitalista e à destruição do Estado, asserção concernente à questão da transição socialista ${ }^{5}$. Poulantzas assume, pois, a tarefa de construção do conceito do político no modo de produção capitalista, vendo-se, porém, obrigado a estabelecer, como ponto de partida da sua empreitada teórica, o conceito de político em geral (SAES, 1998b, p. 46).

O objetivo geral deste artigo é retomar as contribuições de Nicos Poulantzas sobre a operacionalidade do conceito de classe social na análise da reprodução de um modo de produção, bem como na análise da sua transformação. Retomaremos, em primeiro lugar, as críticas desse autor à concepção economicista do conceito de classe, centrandonos no conhecido ensaio de Georg Lukács, "Consciência de Classe", a fim de evidenciar a originalidade das suas formulações. Num segundo momento, consideraremos algumas retificações e desenvolvimentos, realizados por autores brasileiros que compartilham das teses althusserianas, das contribuições de Poulantzas sobre o tema. Por fim, concluiremos este artigo com um balanço da discussão acerca da operacionalidade do conceito de classe na análise da reprodução do modo de produção capitalista, bem como da sua transformação.

\section{O economicismo oculta a revolução}

Em sua abordagem teórica do conceito de classe social, Poulantzas (1975a;1975b), em consonância com as teses desenvolvidas pela corrente althusseriana, estabelece uma linha de demarcação entre a sua definição de classe e as teses que definem a classe (operária)

\footnotetext{
${ }^{5}$ Importa ressaltar que, mesmo que da formulação desses temas não decorra uma reflexão desenvolvida sobre a transição socialista, ela se encontra amparada pela teoria de Lenin do Estado burguês e da sua destruição.
}

cadernos cemarx, no $12-2019 \quad 115$ 
como um resultado exclusivo da estrutura econômica. Importa sublinhar que a ideia comum às diferentes tendências do marxismo economicista é a concepção da mudança histórica como um simples reflexo de uma transformação econômica prévia. As análises guiadas por essa interpretação do processo histórico terminam por descurar, e mesmo por rechaçar, a importância da luta revolucionária como condição prévia à transição socialista. Poulantzas se refere à seguinte passagem de Karl Marx, presente em A miséria da filosofia, que constitui o ponto de partida da sua crítica às interpretações economicistas do conceito de classe:

As condições econômicas, inicialmente, transformaram a massa do país em trabalhadores. A dominação do capital criou para esta massa uma situação comum, interesses comuns. Essa massa é, pois, face ao capital, uma classe, mas ainda não o é para si mesma. Na luta, de que assinalamos algumas fases, esta massa se reúne, se constitui em classe para si mesma. Os interesses que defendem se tornam interesses de classe. Mas a luta entre classes é uma luta política (MARX, 1985, p. 159).

Poulantzas (1975a, p. 57) retoma esta passagem para ressaltar a sua importância para a teoria marxista das classes sociais, criticando, por conseguinte, as interpretações equivocadas que muitos teóricos do marxismo dela fizeram, assinalando, dentre elas, a interpretação de Lukács. O economicismo que Poulantzas critica e combate no interior do campo marxista define o terreno da economia capitalista como o lugar exclusivo da operação de uma contradição antagônica insuperável entre burguesia e classe operária (BOITO JR., 2007a, p. 193). As teses veiculadas pela Segunda Internacional, sobretudo por Karl Kautsky, concebem a classe social como um fenômeno da economia. A consequência teórica e política desta interpretação é conceber a "consciência de classe" como um resultado quase que espontâneo da posição ocupada pelos operários na produção. Logo, a ideia consolidada pela Segunda Internacional é que “(...) a consciência 
de classe seria resultado do crescimento sociodemográfico da classe operária e do suposto processo de homogeneização e simplificação da situação socioeconômica dessa classe" (BOITO JR., 2007a, p. 193-194). Este processo constituiria, por conseguinte, um resultado natural do desenvolvimento do capitalismo.

A visão economicista veiculada pela Segunda Internacional também caracterizou as ideias que predominaram na Terceira Internacional, e obtiveram uma formulação clássica no ensaio de Georg Lukács (2003), intitulado "Consciência de classe" ${ }^{\prime \prime}$. Nesse ensaio de 1920, Lukács apresenta sua definição de classe estabelecendo uma distinção entre "falsa consciência" e "verdadeira consciência" de classe ${ }^{7}$. Vejamos como este autor opera com essas duas noções. De acordo com Lukács (2003), em sua crítica à economia política - sobretudo às teses de David Ricardo e Adam Smith -, Marx teria desvelado o caráter histórico do surgimento das formações sociais, do seu "devir histórico", ou seja, do seu consequente e inevitável "declínio histórico", ao qual as sociedades estariam predestinadas (2003, p. 135). Lukács concebe a esfera produtiva como centro do processo social do desenvolvimento (2003, p. 171), sendo a consciência de classe determinada pelo processo de produção (2003, p. 143). Alega que o "interesse econômico de classe como motor da história" só apareceu no capitalismo, momento em que a essência econômica se manifesta na sua plenitude (2003, p. 155156). É nesse sentido que Lukács concebe tanto a burguesia como o proletariado como "...as únicas classes puras da sociedade", ou seja, as únicas "(...) cuja existência e evolução baseiam-se exclusivamente no desenvolvimento do processo moderno de produção" (2003, p. 156). Apenas a classe que possui um fundamento econômico imediato é a classe que possui a verdadeira consciência (2003, p. 154). A classe que preenche esse pré-requisito é, na sua concepção, o proletariado.

\footnotetext{
${ }^{6}$ Apoiamo-nos aqui nas análises realizadas por Boito Jr. (2007a).

${ }^{7}$ De acordo com Boito Jr. (2007a, p. 194), este ensaio de Lukács foi ignorado em sua autocrítica presente no Prefácio de 1967 à obra História e consciência de classe. Consultar, a esse respeito, Lukács (2003).
} 
Como “(...) o capitalismo é a primeira organização produtiva que, conforme a tendência, impõe-se economicamente em toda a sociedade", a burguesia deveria "estar capacitada" para possuir uma consciência da totalidade do processo de produção (2003, p. 161). No entanto, como o "interesse" da burguesia como produtora de mercadorias foca o "processo de utilização", e não a totalidade do processo produtivo", a "(...) realização da função social do capitalismo pela burguesia" ocorre de maneira inconsciente, irracional, anárquica, ou seja, através de uma "falsa consciência". O proletariado se distingue, pois, de todas as outras classes "(...) por constituir ele próprio a essência das forças motrizes e, agindo de maneira centralizada, por influenciar o centro do processo social de desenvolvimento" (2003, p. 171). A consciência de classe do proletariado constitui, na concepção de Lukács, "(...) a última consciência de classe na história da humanidade", devendo coincidir "com o desvendamento da essência da sociedade" e, ao mesmo tempo, "tornar-se uma unidade cada vez mais íntima da teoria e da práxis" (2003, p. 174). Para Lukács, o proletariado já se constitui em proletariado em função do processo produtivo, ou seja, o proletariado é a única classe que possui a verdadeira consciência de classe. No entanto, a despeito do avançado desenvolvimento capitalista, no momento em que Lukács redigia seu ensaio, que já caracterizava muitos países europeus, bem como os Estados Unidos, o "destino da revolução", imanente à consciência de classe do proletariado, não foi alcançado. Lukács é ciente, tal como assinala Boito Jr. (2007a, p. 194), da inexistência, naqueles países, de uma “(...) classe operária organizada lutando por aqueles que seriam os seus interesses". Ainda segundo Boito Jr., a fim de solucionar este impasse, qual seja, a não realização pelo proletariado do seu dever histórico - a sua "libertação de classe" e a consequente "supressão da sociedade de classes em geral" (LUKÁCS, 2003, p. 174) - Lukács recorre à ideia de falsa consciência. Portanto, é a partir desse momento que descreve a "consciência de classe" como superação dialética do "interesse imediato", "momentâneo", "individual", "do estado de consciência psicológica dos proletários", para que seja alcançado o seu

118 Nicos Poulantzas,... 
"fim último", a "totalidade", a "verdade", o proletariado deixando de ser uma "classe em si" para se tornar uma "classe para si". Na visão de Lukács, a separação entre a "luta econômica" do proletariado e a "luta política" constitui um desvio explicável pela "falsa consciência", “(...) já que é natural a toda luta econômica converter-se em luta política" (LUKÁCS, 2003, p. 175). De acordo com Boito Jr., a falsa consciência, sempre definida por Lukács em termos negativos - momentânea", "individual", "psicológica" - não passa de um artifício ao qual o autor recorre para tentar superar as dificuldades do que não consegue explicar. Por conseguinte, "O impasse teórico [do ensaio de Lukács] ilustra as dificuldades insuperáveis da posição que consiste em apresentar a economia capitalista como algo suficiente para definir a classe operária" (BOITO Jr., 2007a, p. 197).

\section{Poulantzas e a crítica à interpretação marxista economicista do conceito de classe}

Poulantzas (1975a) denomina a interpretação de Lukács como uma leitura de "histórico-genética" do marxismo, de modo que, ao interpretar os textos de Marx na sua literalidade, neles encontrariam “(...) uma historiografia da 'gênese' da classe social”. Qual é o significado desta historiografia genética, de acordo com Poulantzas? A constituição dos diversos "níveis" teóricos de análise de Marx, ou seja, os diferentes níveis de abstração ${ }^{8}$, são lidos como “(...) etapas históricas da formação de uma classe: massa indiferenciada de indivíduos no

\footnotetext{
${ }^{8}$ A tese de Althusser em "Sobre o Trabalho Teórico" é de que a história deve ser analisada a partir de conceitos abstratos e gerais que transcendem longos e diferentes períodos históricos correspondentes a distintas regiões geográficas. Para que essa análise possa ser realizada, faz-se necessária uma hierarquização desses conceitos: num nível mais abstrato, temos os conceitos supramodais (Estado em geral, modo de produção em geral, etc.); num segundo nível de abstração encontramos os conceitos modais (o modo de produção capitalista, o modo de produção feudal, etc.); já o terceiro nível de abstração - o nível mais concreto e determinado - trabalha com o conceito de formação social. Ver, a esse respeito, Boito Jr. (2013).
} 
início, ela se organizaria em seguida em uma classe-em-si, para acabar, finalmente, na classe-para-si" (1975a, p. 57). Além de constituir uma interpretação historicista dos textos de Marx, tal leitura, na perspectiva de Poulantzas, incorre no erro da "transposição de problemática", para empregar uma expressão formulada pelo cientista político Décio Saes (1998c): a "importação, para o interior do marxismo, do esquema ontológico-genético da história, no sentido hegeliano do termo, e que se desenvolve sobre o tema 'são os homens que fazem a sua própria história"' (POULANTZAS, 1975a, p. 58).

Poulantzas critica Lukács por atribuir aos agentes da produção o estatuto de "atores-produtores", ou seja, "sujeitos criadores das estruturas". Na concepção historicista da história, diz Poulantzas, "A própria distribuição dos agentes em classes sociais é reportada ao processo de concepção historicista, de criação-transformação das estruturas sociais pelos 'homens'”'. Essa concepção ignora dois fatos essenciais: “(...) que os agentes da produção, por exemplo, o trabalhador assalariado e o capitalista, enquanto 'personificações' do Trabalho assalariado e do Capital, são considerados por Marx como os suportes ou os portadores de um conjunto de estruturas"; e "(...) que as classes sociais nunca foram teoricamente concebidas por Marx como a origem genética das estruturas (...)" (POULANTZAS, 1975a, p. 60). “As classes sociais", define Poulantzas (1975c, p. 13-14), "são conjuntos de agentes sociais determinados principalmente, mas não exclusivamente, por seu lugar no processo de produção", já que "o político e o ideológico (...) desempenham igualmente um papel muito importante [num modo de produção]". Como bem sublinha Galvão (2011, p. 109), "Não se trata (...) de um determinismo unilateral, mas de uma multideterminação". Nesse sentido, de acordo com Poulantzas, a definição da classe social não pode se limitar à sua posição no processo de produção:

As classes sociais não se apresentam (...) como o efeito de um nível estrutural particular - por exemplo, a estrutura econômica - sobre outro nível estrutural - a estrutura política ou a estrutura 
ideológica, no interior, portanto, da estrutura, mas, antes, como o efeito global das estruturas no domínio das relações sociais, os quais conotam, nas sociedades de classe, a distribuição dos agentes-suportes por classes sociais: e isso na medida em que as classes sociais determinam o lugar dos agentes suportes relativamente às estruturas de um modo de produção e de uma formação social (1975a, p. 62).

É no nível das práticas em que é possível detectar a existência das classes, sendo estas consideradas efeitos das estruturas: "As classes sociais não abrangem as instâncias estruturais, mas as relações sociais: estas relações sociais consistem em práticas de classe, o que quer dizer que as classes sociais não são concebíveis senão em termos de práticas de classe" (POULANTZAS, 1975a, p. 87). A fim de elucidar o caráter anti-historicista da proposição "a luta de classes constitui o motor da história", Poulantzas (1975a, p. 35) ressalta a necessidade de se considerar o lugar do político, mais particularmente, da prática política nas suas relações com a história (1975a, p. 37). Nesse sentido, a "prática política" constitui o "motor da história" apenas na medida em que o resultado, o produto desta prática seja a transformação da unidade de uma formação social. Poulantzas (1975a, p. 41) identifica, portanto, a existência de dois tipos de "práticas políticas": a) uma prática política cujo resultado é "(...) a manutenção da unidade de uma formação, de um dos seus estágios ou fases, ou seja, de sua não transformação"; b) uma prática política que tem como objetivo "o Estado como estrutura nodal de ruptura desta unidade, na medida que ele é o fator de coesão: neste contexto, o Estado poderá, por outro lado, ser visado como fator de produção de uma nova unidade, de novas relações de produção". Neste ponto é importante ressaltar que, para a corrente althusseriana, as estruturas que integram a "totalidade social" só existem através das suas práticas, consideradas na sua totalidade como práticas sociais estruturadas. Já as práticas sociais antagônicas, disruptivas, que resultam de relações antagônicas entre os agentes sociais, ou 
seja, a luta de classes no sentido forte, não podem ser consideradas práticas estruturadas; elas só podem ser concebidas como “(...) práticas antiestruturais, que levam à ruptura um modelo particular de funcionamento das sociedades humanas" ${ }^{9}$ (SAES, 1998c, p. 79). É esta questão teórica - correta, segundo a interpretação der Saes - que conduz Poulantzas a formular uma solução para esse problema a fim de evitar uma "identificação indevida entre estrutura e prática". Nesse sentido, Poulantzas estabelece a necessidade de reconhecer que "(...) uma instância estrutural, do mesmo modo, não constitui diretamente uma prática", já que instância e prática correspondem a "(...) dois sistemas - ou séries de relações reguladas - particulares, possuindo as suas estruturas próprias" (1975a, p. 88). Poulantzas introduz em seu sistema teórico uma diferenciação entre estruturas e práticas para tentar explicar as diferentes práticas de classes e suas diferentes formas de luta - luta econômica e luta política. Saes (1998c, p. 79), ao se referir a esse impasse, considera correta a questão teórica que motivou aquela formulação de Poulantzas: a existência de um tipo de prática que não pode ser considerada como prática estruturada. Também considera correta a postura de Poulantzas de situar as classes sociais no nível das práticas, considerando essas práticas como efeitos das estruturas. Ou seja, os agentes se comportam de maneiras distintas por ordem dos efeitos articulados das estruturas jurídico-políticas e econômicas. No entanto, atenta para a inadequação da formulação de Poulantzas, constatando nela a presença de dois erros: a) ao distinguir em termos absolutos "estruturas e "práticas", Poulantzas considera que tanto as práticas como as estruturas são estruturadas. No entanto, apenas as práticas podem ser estruturadas, e não as estruturas. Poulantzas também faz o conceito de estrutura "girar no vazio", como se a estrutura pudesse deixar de se referir a alguma prática; b) Poulantzas erra ao conceber a luta de classes no sentido do termo como um conjunto de práticas sociais

${ }^{9}$ É Décio Saes quem depreende esse entendimento das estruturas a partir do seu trabalho de retificação e desenvolvimento das teses althusserianas.

122 Nicos Poulantzas,... 
estruturadas. Logo, ainda de acordo com Saes (1998c, p. 79), o problema de Poulantzas não reside “(...) na indicação do caráter oposicional ou contraditório das práticas de classe; nem, consequentemente, em sugerir que tais práticas não constituem uma emanação das estruturas integrantes da 'totalidade social'”. O principal problema de sua formulação consiste em não considerar a luta de classes no sentido forte do termo como "práticas sociais desestruturadas e - mais ainda - antiestruturais".

\section{A estrutura social e o sistema de lugares diferenciados}

Saes (1998c) depreende da reflexão de Poulantzas acerca das práticas de classes que, no funcionamento reprodutivo de qualquer modo de produção, o sistema de lugares diferenciados que designa, respectivamente, trabalhadores e proprietários dos meios de produção, implantado no processo social de produção, ou seja, na estrutura econômica, não se exprime automaticamente, nos planos ideológico e político, como contradição entre classes sociais antagônicas. Nesse sentido,

A possibilidade de realizar-se a operação teórica de classificação dos homens segundo o lugar por eles ocupados nas relações de produção não significaria, entretanto, que cada uma dessas classes de homens já atuaria como uma classe social, isto é, como um grupo social coeso, voltado sistematicamente para a destruição das relações de produção vigentes, ou, inversamente, para a conservação dessas relações de produção, já ameaçadas (SAES, 2003, p. 249).

A "assimetria" entre as práticas reprodutivas de classes e aquelas antiestruturais se explica pelo efeito dissolvente das demais estruturas sociais, já que estas "trabalham" regularmente para impedir que a classe dominada se torne ideológica e politicamente autônoma, isto 
é, que se converta em força revolucionária. Nesse sentido, para que a prática da classe dominada se transforme em prática revolucionária, é preciso que ela se subtraia às estruturas do modo de produção, ou seja, que os efeitos ideológicos que operam sobre elas cessem de funcionar, e que se enquadre numa "situação superestrutural" alternativa (SAES, 1998c, p. 80).

Com o objetivo de desenvolver a relação entre luta, classes e prática antiestrutural, Saes (1998c) introduz, em sua redefinição do conceito althusseriano de modo de produção, uma distinção entre "sistema de grupos funcionais", concernentes ao funcionamento reprodutivo de um modo de produção e o "sistema de antagonismo de classe", que se refere à transição de um modo de produção a outro. Tal distinção constituiria na renomeação, nos termos do marxismo clássico, de um "sistema de classe em si" e um "sistema de classe para si". Saes argumenta que o primeiro sistema resulta do funcionamento articulado das estruturas do modo de produção, e seu "equilíbrio instável" é mantido graças aos efeitos ideológicos da ação do direito burguês conjugada à ação do burocratismo, que dificultam o surgimento de uma prática de classe antiestrutural. Já o segundo sistema "se delineia quando as estruturas deixam de produzir os efeitos sobre os 'suportes humanos', isto é, em situações de crise do modo de produção. Nessas situações, o sistema de grupos funcionais cede lugar à luta de classes, no sentido forte do termo" (SAES, 1998c, p. 88). A passagem do sistema de grupos funcionais ao sistema de antagonismo de classe deve ser apreendida enquanto uma ruptura qualitativa, já que é qualitativamente distinta da orientação das práticas sociais, econômicas e políticas em um sistema e outro (SAES, 1998c, p. 120, nota 151). Logo, os conflitos funcionais e a reprodução de um modo de produção não devem ser confundidos teoricamente com luta de classes. No entanto, Saes dá um passo a mais em sua definição, afirmando que tampouco os grupos funcionais devem ser confundidos teoricamente com classes sociais (2003, p. 253).

O próprio Althusser, ao se referir à prática de classe, também identifica a necessidade de diferenciar uma prática reprodutiva de classes

\begin{tabular}{l|l}
\hline 124 & Nicos Poulantzas,,..
\end{tabular} 
de uma prática revolucionária de classes. Em "Resposta a John Lewis", ao criticar a concepção idealista de classes, ou seja, aquela que veicula uma existência das classes anterior à luta de classes, Althusser (1978, p. 27) afirma ser impossível "separar as classes da luta de classes", já que a existência de classes em uma sociedade resulta da exploração de uma classe por outra. Ao mesmo tempo, Althusser define a luta de classes em termos revolucionários, já que “(...) o poder revolucionário das massas só é poder em função da luta de classes". E declara que o fator que constitui as classes enquanto "classes" e enquanto "classes antagônicas" é a luta de classes (1978a, p. 28). Já em "Prática teórica e luta ideológica", Althusser (1986, p. 54-55) chama a atenção para a existência, no interior da ideologia geral, de "tendências ideológicas diferentes que expressam as 'representações' das diferentes classes sociais", como a ideologia "burguesa", "pequeno-burguesa", "proletária". De qualquer forma, essas tendências ideológicas se encontram subordinadas à ideologia da classe dominante, pois esta ideologia é a que prevalece. Althusser (1986, p. 63) ressalta, ainda, a necessidade de transformação da ideologia da classe operária que permanece refém da ideologia burguesa e que essa transformação só pode ser pensada a partir de uma perspectiva revolucionária.

Saes (1998c), por sua vez, argumenta que o estabelecimento da diferenciação entre um "sistema de grupos funcionais" e um "sistema de antagonismo de classe" não exclui do terreno da reprodução social a existência de conflitos numa sociedade estruturada, cujo funcionamento ocorre de maneira estável. Dito de outro modo, a vigência da estrutura não exclui a emergência de conflitos, sejam eles econômicos ou políticos. Saes (2017) define estes conflitos como divergências coletivas que não possuem um caráter irreconciliável. Logo, esses conflitos podem ser resolvidos dentro dos limites impostos pelas estruturas do modo de produção vigente. Importa ressaltarmos que a extensão desses limites está subordinada à análise de cada modo de produção particular. Saes também ressalta que o papel das estruturas não é o de imobilizar completamente a vida social, mas de restringir a dinâmica 
social dentro de certos limites. Isso significa evitar que os conflitos coletivos, que ocorrem em qualquer sociedade de classes, possam se converter em contradições, ou seja, em um antagonismo de classe, cuja tendência é a transformação daquela sociedade. Nesse sentido, Saes argumenta que é possível observar a emergência no capitalismo, em seus períodos de estabilidade, de conflitos funcionais tanto na esfera econômica quanto na esfera política. Em relação aos conflitos econômicos, Saes (1998a; 1998b) cita como exemplo os conflitos entre capital e trabalho assalariado, caracterizados por Poulantzas (1975a) como "lutas econômicas". Tais conflitos podem ser caracterizados como aqueles concernentes ao nível dos salários reais, à duração da jornada de trabalho, às condições materiais do processo de trabalho. Esses conflitos não podem ser considerados por si só como desestabilizadores do sistema capitalista, mas sim, funcionais à reprodução do sistema, já que contribuem, independentemente das intenções dos agentes, para o seu desenvolvimento superior. Saes também observa que, da esfera política, podem emergir conflitos funcionais que oponham, por exemplo, o Estado capitalista ao Povo. Esses conflitos giram, pois, em torno de maiores conquistas de direitos civis, por exemplo, e podem ser considerados funcionais apenas se permanecerem circunscritos ao plano constitucional, não questionando, por conseguinte, a capacidade decisória e repressora da burocracia estatal, bem como a detenção do poder estatal pela classe capitalista.

\section{Classe potencial, classe ativa e a luta de classes}

Boito Jr. (2007), ao refletir sobre a constituição da classe operária, demonstra sua concordância com os aspectos gerais das formulações de Poulantzas e Saes. No entanto, no desenvolvimento dos seus argumentos, aflora uma consideração que identifica uma contradição nas teses desenvolvidas por Saes. Tal como Saes e Poulantzas, Boito Jr. (2007a, p. 195) concebe que a classe social é um fenômeno concomitantemente econômico, político e cultural, objetivo e subjetivo. 
Atenta, igualmente, para a necessidade de diferenciação, na análise da formação das classes sociais, da classe dominante da classe dominada. E considera, por fim, que a formação da classe dominante, no funcionamento reprodutivo de uma sociedade qualquer, já está dada; no entanto, a formação da classe dominada constitui tão somente uma possibilidade real.

Levando em consideração, em sua análise, o conceito poulantziano de Estado capitalista (POULANTZAS, 1975a; 1975b), bem como o conceito de Estado burguês, desenvolvido por Saes (1985; 1998a), Boito Jr. argumenta que, no modo de produção capitalista, a classe dominante já se encontra formada. A despeito da existência de diferentes frações burguesas - grande e média burguesia, burguesia industrial, comercial, financeira etc. - “(...) todo capitalista individual conhece seus interesses de classe e, regra geral, age nos limites dados por esse interesse" (BOITO JR., 2007a, p. 195). Isso se explica porque o Estado burguês nada mais é do que a burguesia organizada como classe. De acordo com as análises do próprio Saes (1985; 1998a), é o Estado burguês que cria as condições ideológicas necessárias para a reprodução das relações de produção capitalistas, já que o Estado burguês organiza de um modo particular - o modo burguês - a dominação de classe, ou seja, a dominação burguesa. A constituição da burguesia em classe dominante é o que permite Boito Jr. defini-la como uma classe ativa que se encontra presente tanto no nível político como no nível econômico. Para contrapor a condição da burguesia como classe ativa na sociedade capitalista, Boito Jr. (2007b) cita a condição de classe subordinada que a burguesia desempenhava na Europa absolutista, quando predominava o Estado monárquico-feudal. De acordo com a sua análise, o Estado monárquico feudal representava os proprietários feudais organizados em classe dominante; já a burguesia procurava se integrar à economia da sociedade feudal. Antes da revolução burguesa, a burguesia se encontrava, portanto, na condição de classe potencial. "Foi o processo de revolução burguesa que transformou a burguesia de classe potencial, presente de modo latente no processo econômico, em classe ativa, 
atuante como um coletivo organizado na cena política e social" (2007a, p. 196) ${ }^{10}$.

\section{Conclusão}

Ao analisar as relações de produção capitalista em PPCS, Poulantzas identifica uma contradição objetiva do processo de trabalho típica da grande indústria moderna: a oposição entre a independência e a dependência do produtor direto no processo de trabalho: o caráter privado - independente - dos trabalhos na grande indústria dissimula a dependência real dos produtores introduzida pela alta socialização do trabalho que caracteriza a grande indústria moderna. É tal contradição, argumenta Saes (1998a), que determina a formação, no produtor direto, de duas tendências: a tendência ao isolamento e a tendência à ação coletiva, sendo que a dominância de uma tendência pela outra - da tendência à ação coletiva pela tendência ao isolamento - só pode ser garantida pela esfera do Estado, que neutraliza, através dos efeitos ideológicos do direito burguês conjugados aos efeitos ideológicos do burocratismo, a tendência dos produtores diretos à ação coletiva. Logo, de acordo com Boito Jr., a organização de coletivos com interesses opostos, no processo de produção, apresenta-se como uma possibilidade. Na esfera econômica do modo de produção capitalista “(...) estão presentes, potencialmente, tanto classes antagônicas quanto grupos que cooperam entre si (...)" (BOITO JR., 2007a, p.197). Nesse sentido, a classe operária, cuja existência no terreno da economia capitalista

${ }^{10}$ Galvão (2011) critica o entendimento de Boito Jr. e Saes de que a luta de classes aplicar-se-ia apenas aos processos de transição. Argumenta, nesse sentido, que as lutas classificadas quanto ao seu aspecto "funcional à reprodução dos sistemas" (para empregar aqui a ideia de Saes), mesmo se mostrando difusas, podem "provocar efeitos importantes para o desdobramento da luta de classes" (2011, p. 115). Propõe, assim, que as diferentes dimensões das lutas de classes, que ocorrem sem que ameacem de maneira imediata a reprodução do capitalismo, sejam pensadas a partir de uma perspectiva mais dinâmica. 
é potencial, só adquire uma existência ativa, ou seja, só se constitui em classe, quando o antagonismo latente se tornar manifesto. E, para que isso aconteça,

(...) é necessária a combinação de inúmeros fatores de ordem econômica, política e ideológica - situação do emprego e do salário, situação do sistema de alianças que sustenta o bloco no poder burguês, eficácia da ideologia e do programa socialista para responder aos problemas colocados na ordem do dia pela sociedade capitalista em determinada etapa do seu desenvolvimento (BOITO JR., 2007a, p. 197).

É somente numa situação de crise revolucionária que o proletariado se constitui em classe; a crise revolucionária só ocorre no terreno das formações sociais e em conjunturas específicas, em virtude da existência múltiplos fatores contraditórios e sobredeterminados. É o próprio Lenin quem oferece esta definição de crise revolucionária. Não há, pois, na sua análise, lugar para uma contradição simples entre "trabalho" e "capital" como propulsora dessa crise. Sendo assim,

Só quando os "de baixo" não querem o que é velho e os "de cima" não podem como dantes, só então a revolução pode vencer. Esta verdade exprime-se de outro modo, com as palavras: a revolução é impossível sem uma crise nacional (tanto dos explorados como dos exploradores). Por conseguinte, para a revolução é necessário, em primeiro lugar, que a maioria dos operários (ou pelo menos a maioria dos operários conscientes, pensantes, politicamente ativos) compreenda plenamente a necessidade da revolução e esteja disposta a dar a vida por ela; em segundo lugar, é preciso que as classes dirigentes atravessem uma crise governamental que arraste para a política mesmo as massas mais atrasadas (o sintoma de toda revolução autêntica é a rápida 
decuplicação ou centuplicação da quantidade de representantes dos trabalhadores e da massa oprimida, antes apática, aptos para a luta política), que enfraqueça o governo e torne possível aos revolucionários o seu rápido derrubamento (LENIN, 1980, p. 325).

O esforço teórico empreendido por Décio Saes na retificação do conceito ampliado de modo de produção desenvolvido pelos autores althusserianos tem como principal aspecto mobilizador a explicação da mudança social a partir do modelo teórico althusseriano. A fim de distinguir metodologicamente reprodução de transição, Saes, no nível mais geral da análise (ou no nível supramodal) identifica os grupos funcionais com a reprodução de um modo de produção e as classes sociais com a transformação social. No entanto, em sua análise específica do modo de produção capitalista e do Estado burguês, a noção de grupo funcional aplicada à burguesia se mostra incompatível com a própria redefinição, operada por Saes (1985; 1998a), do conceito poulantziano de Estado capitalista em Estado burguês, já que este conceito implica um caráter ativo da classe burguesa numa formação social capitalista. Atento a esta incongruência, Boito Jr. aponta o caráter ativo e potencial, respectivamente, das classes dominantes e dominadas no funcionamento reprodutivo de um modo de produção qualquer, o que significa salvaguardar o conceito de classe na análise da reprodução do todo social.

\section{Referências bibliográficas}

ALTHUSSER, Louis. "Resposta a John Lewis". In: Posições I. Rio de Janeiro: Edições Graal, 1978.

ALTHUSSER, Louis. "Práctica teórica y lucha ideológica". In: La filosofía como arma de la revolución. 16 $6^{\underline{a}}$ ed. Mexico, DF: Pasado y Presente, 1986. 
ALTHUSSER, Louis. Pour Marx. $3^{\mathrm{a}}$ ed. Paris: La Découverte/Poche, 2005.

ALTHUSSER, Louis. Sobre o trabalho teórico. Lisboa: Editorial Presença, $\mathrm{s} / \mathrm{d}(\mathrm{a})$.

BOITO JR., Armando. "A (difícil) formação da classe operária". In: Estado, política e classes sociais. São Paulo: Unesp, 2007a, pp. 189200.

BOITO JR., Armando. "Pré-capitalismo, capitalismo e resistência dos trabalhadores: elementos para uma teoria da ação sindical". In: Estado, política e classes sociais. São Paulo: Unesp, 2007, pp. 155188.

BOITO JR., Armando."Indicações para o estudo do marxismo de Althusser". In: Novos Temas, São Paulo: Edição do Instituto Caio PradoJr., no 09, segundo semestre de 2013, pp.153-182 (Disponível em:<https://edisciplinas.usp.br/pluginfile.php/3161715/mod_ resource/content/1/BOITO\%20JR.\%2C\%20Armando.\%20 Indica $\%$ C $3 \% \mathrm{~A} 7 \% \mathrm{C} 3 \% \mathrm{~B} 5$ es $\% 20$ para $\% 20$ estudo $\% 20 \mathrm{do} \% 20$ marxismo\%20de\%20Althusser.\%20Novos\%20Temas.pdf)>.

GALVÃO, Andréia. "Marxismo e movimentos sociais". In: Crítica Marxista, São Paulo: Fundação Editora da Unesp, nº 32, 2011, pp. 107-126.

LAZAGNA, Angela. O político na transição socialista. Explicação e retificação da contribuição da corrente althusseriana. Campinas, 2017. Tese (Doutorado em Ciência Política). Faculdade de Filosofia e Ciências Humanas, Universidade Estadual de Campinas. 
LENIN, Vladimir I. "A doença infantil do'esquerdismo' no comunismo". In: Obras Escolhidas. São Paulo: Editora Alfa-Ômega, 1980, volume 3, pp. 275-349.

LUKÁCS, Georg. História e consciência de classe. Estudos sobre a dialética marxista. São Paulo, Martins Fontes, 2003.

MARX, Karl. A miséria da filosofia. São Paulo: Global Editora, 1985.

POULANTZAS, Nicos. Povoir politique et classes sociales. Volume I. Paris: François Maspero, 1975a.

POULANTZAS, Nicos. Povoir politique et classes sociales. Volume II. Paris: François Maspero, 1975b.

POULANTZAS, Nicos. As classes sociais no capitalismo hoje. Rio de Janeiro: Zahar Editores, 1975c.

SAES, Décio. A formação do Estado burguês no Brasil (1888-1891). Rio de Janeiro: Paz e Terra, 1985.

SAES, Décio. "Marxismo e história". In: Crítica Marxista. São Paulo: Brasiliense, $\mathrm{n}^{\mathrm{o}}$ 01, 1994, pp. 39-59.

SAES, Décio. Estado e democracia: ensaios teóricos. Coleção Trajetória 1. Campinas: Gráfica do IFCH/Unicamp, 1998a, 2ª edição.

SAES, Décio. "A questão da autonomia relativa do Estado em Poulantzas". In: Crítica Marxista. Rio de Janeiro: Xamã, no 07, 1998b, pp. 46-66. 
SAES, Décio. "O impacto da teoria althusseriana da história na vida intelectual brasileira". In: QUARTIM de MORAES, João (Org.). História do Marxismo no Brasil. Vol. III. Teorias. Interpretações. Campinas: Editora da Unicamp, 1998c, pp. 11-122.

SAES, Décio. "Considerações sobre a análise dos sistemas de classe". In: GALVÃO, Andreia (Org.). Marxismo e Ciências Humanas. São Paulo: Xamã; FAPESP; Cemarx (IFCH-Unicamp), 2003, pp. 248256.

SAES, Décio. "Althusserianismo e dialética". In: Demarcaciones, $\mathrm{n}^{\text {}}$ 05, 2017. Disponível em: <http://revistademarcaciones.cl/wpcontent/uploads/2017/06/Saes-Althusserianismo-e-dial_ctica. pdf.> 
